\title{
New fusible binder additives for composite explosives
}

\author{
Marina Komarova, Aleksey Vakutin*, Nikolai Kozyrev, Gennady Sukhanov and Sergey Il'yasov \\ Institute for Problems of Chemical and Energetic Technologies, SB RAS, 1 Sotsialisticheskaya street, Biysk, 659322, Russia
}

\begin{abstract}
Occupational safety in manufacturing powerful melt-cast composite explosives requires replacement of conventional fusible binders, as trotyl and dinitrazapentane, by less sensitive compounds. To solve this challenge, insensitive 3-nitro-1,2,4-triazole derivatives (1-, 2-methyl, tert-butyl, ethoxymethyl) and their eutectic mixtures with furazanyl furoxane can be used in formulations with 1,3,5,7-tetranitro1,3,5,7-tetrazocane (octogen, HMX) and 6-nitrohexaazaisowurtzitane (CL-20). Our studies shows quite low sensitivity impact of the nitrotriazole derivatives $(\geq 500 \mathrm{~mm}$ at a load weight of $10 \mathrm{~kg}$ ), their melting temperatures $\left(56 \ldots 94{ }^{\circ} \mathrm{C}\right)$, and their eutectic temperatures with furazanyl furoxane $\left(57 \ldots 62^{\circ} \mathrm{C}\right)$. For HMXbased composite explosives, the optimum options are ethoxymethyl-3-nitro-1,2,4-triazole and its eutectic melt with furazanyl furoxane (80/20 weight ratio), while for CL-20-based formulations, the appropriate additives were 1-methyl-3-nitro-1,2,4-triazole and its eutectic melt with furazanyl furoxane (80/20 weight ratio). Phase diagrams of the new fusible binder additives are also given. The data were obtained by differential scanning calorimetry(DSC).
\end{abstract}

\section{Introduction}

Application of more powerful explosives increases the risks associated with production, processing, storage, and application occupational hazards of composite explosives. Therefore, greater attention should be paid to the safety problems, especially when high-sensitivity powerful explosives such as octogen (HMX), furazanyl furoxane (BNFF) and hexanitrohexaazaisowurtzitane (CL-20) are employed. Hence, the search for new solutions is a hot topic.

In composite explosives produced by the casting method to bond the filler (HMX, CL-20, etc.), fusible binder additives are utilized. The conventional fusible binders are trotyl (TNT) and dinitrazapentane (DNP) whose mechanical sensitivities are considered acceptable but not sufficient to design explosives with reduced sensitivity and enhanced power. Some derivatives of ploynitrogen heterocyclic compounds are promising. These compounds feature a high enthalpy of formation and a fairly high density, and contain energetic groups rich in nitrogen $[1,2]$.

Nitrotriazole derivatives have very low sensitivities to impact and friction, and an appropriate melting temperature for technological processing. For instance, 1-methyl-3-nitro-1,2,4-triazole is close to TNT in some properties (density, oxygen balance, detonation rate) but its melting temperature $\left(\sim 65^{\circ} \mathrm{C}\right)$ is more appropriate for casting, and it is also highly safe.

The sensitivity level is lower than that of conventional fusible binders, which makes it possible to improve the energetic performance of nitrotriazole derivatives by means of powerful BNFF. Due to melting at $107 \ldots 111^{\circ} \mathrm{C}$ [3-8] BNFF can form eutectic mixtures with other ingredients of composite explosives, including TNT [4, 8, 9]. It was experimentally shown [8] that TNT/BNFF eutectic systems had better energetic and technical characteristics than TNT alone and lower sensitivities to impact and friction than BNFF. The regulating role of the variation of the TNT and BNFF ratio was also well shown. Thus, the replacement of TNT and DNP by nitrotriazole derivatives or by their eutectic mixtures with BNFF for use in HMX and CL-20 formulations is of interest in terms of designing new and optimizing the existing composite explosives.

The present study reports experimental results of developing new fusible binder additives and composite explosives on their basis.

\section{Experimental part}

\subsection{Materials}

To prepare fusible binder additives, we synthesized highenergy materials on the basis of nitrogen-containing heterocycles-nitrotriazole derivatives under laboratory conditions. 1-Methyl-3-nitro-1,2,4-triazole $(\mathrm{Me} 3 \mathrm{H})$ and 2-methyl-3-nitro-1,2,4-triazole $\quad(2 \mathrm{Me} 3 \mathrm{H}) \quad$ were synthesized by alkylating 3-nitro-1,2,4-triazole with methyl iodide and dimethyl sulfate in the presence of alkali [10, 11]. Ethoxymethyl-3-nitro-1,2,4-triazole (EOM) was synthesized by acid-catalyzed reaction between the corresponding heterocyclic and aliphatic alcohols. Tert-butyl-3-nitro-1,2,4-triazole (tBu3H) was prepared by alkylation of 3-nitro-1,2,4-triazole with tertbutyl alcohol in the presence of catalytic amounts of sulfuric acid [12]. The said nitrotriazole derivatives

Corresponding author: alex-wakutin@e-mail.ru 
under normal conditions are solids with a melting point below $94{ }^{\circ} \mathrm{C}$ (Table 1$)$.

We also used commercial conventional fusible binders (Producer, Russia) as 2,4-dinitrazapentane (DNP) and 2,4,6-trinitromethylbenzene (trotyl, TNT). As the ingredient of the fusible binder additives, we used the powerful explosive 3,4-bis(4- nitrofurazanyl-3)furoxane (BNFF) prepared under laboratory conditions in a pilot setup [13].

The fusible binder additives were made as follows: the components were powdered and mechanically mixed in different weight ratios of 20/80, 40/60, 50/50, 60/40 and $80 / 20$. The ready-made mixtures were placed into fluoroplastic cups, heated in a vacuum oven to a temperature close to the melting point of the highmelting ingredient BNFF (to $115^{\circ} \mathrm{C}$ ), and then held at this temperature until the mixtures turned into the liquid state. The resultant melts were cooled at $+24 \pm 1^{\circ} \mathrm{C}$. The melts containing less than a half of BNFF easily crystallized under normal conditions. The melts containing more than a half of BNFF experienced difficulties, and such melts were put into a cooling chamber for $3 \mathrm{hrs}$ to lower their temperature to $4^{\circ} \mathrm{C}$. After being cured, all the samples were held at $24 \pm^{\circ} \mathrm{C}$ for $24 \mathrm{~h}$ to complete the process. The samples were then ground and poured into glass sample bottles with caps, and stored in a sealed package under normal conditions.

Commercially available octogen (HMX, Producer, Russia)) and hexanitrohexaazaisowurtzitane (CL-20) were used to make explosive formulations. The HMX and CL-20 crystals were mechanically mixed with the pulverized fusible binders in a weight ratio of 50/50. The mixtures contained in the fluoroplastic cups were heated to the final melting point of the binder additive (Table 2), stirred and cooled. The samples thus obtained were characterized by the methods described hereinafter.

\subsection{Measurement methods}

For prediction of the properties of materials and explosive formulations, we used a differential scanning calorimetry (DSC) by recording the energy required for temperature equalization of a test substance and a reference standard, depending on time and temperature [14]. The experiments were done on a Mettler Toledo DSC $822^{\mathrm{e}}$ modular calorimeter (Switzerland) in a temperature range from $-65{ }^{\circ} \mathrm{C}$ to $+700{ }^{\circ} \mathrm{C}$. The calorimeter was equipped with a heat flux sensor and an analog converter; the highest programmable sample heating rate was $250{ }^{\circ} \mathrm{C} / \mathrm{min}$ and the measurement error was $\pm 0.2{ }^{\circ} \mathrm{C}$. The instrument was part of the $\mathrm{STAR}^{\mathrm{e}}$ complex measuring system (Thermal Analysis System Software). The instrument was calibrated against heat flux and melting temperature of indium (In, $99.999 \%$ purity) and zinc ( $\mathrm{Zn}, 99.998 \%$ purity) by using dedicated test programs.

The samples of the high-energy materials and explosive formulations in the quantity of $0.7-3.5 \mathrm{mg}$ were placed into aluminum melting crucibles with perforated lids and heated from $+25^{\circ} \mathrm{C}$ to $+125^{\circ} \mathrm{C}$ or to $+350{ }^{\circ} \mathrm{C}$, at a heating rate of $10{ }^{\circ} \mathrm{C} / \mathrm{min}$, in dynamic nitrogen atmosphere (nitrogen gas purge rate was 60 $\mathrm{ml} / \mathrm{min}$ ). The initial information acquired by the $\mathrm{STAR}^{\mathrm{e}}$ measuring system was processed in the $\mathrm{STAR}^{\mathrm{e}}$ software v. 14.00. Numerical values of the melting heat $\left(Q_{m}\right)$ and decomposition heat $\left(\mathrm{Q}_{\mathrm{d}}\right)$ were thus acquired. The heat effects were estimated from the area of the heat effect limited by the DSC graph and by the corresponding baseline (program option 'Integration'). The following baselines were used: 'Tangential Left' - a tangent to the DSC curve, drawn from the left border (for integration of melting peaks with subsequent decomposition); 'Spline' - lines based on two tangents drawn from the left and right borders and connected by a smooth transition line (for overlapping effects). The temperature values of the heat effects were determined from the intercrossing of the tangents drawn to the peak (program option 'Peak') [15].

The morphological features of the starting materials and final composites (crystal surface and size, surface of melts, and so on) were visualized by optical methods. A Motic DMBA-300 Professional Series digital optical microscope (China) was employed with a built-in video camera, computer interface and Motic Images Plus 2.0 image processing software. Zooms were x100, 400 and 1000. The crystal sizes were determined from the plane projections of their images. A comparative analysis of the crystal surface images was used to pre-check the compatibility (no reaction) with the nitrotriazole derivatives and fusible binder additives.

To determine the chemical stability of the highenergy compounds, a Crystal-2000M instrument (gas chromatograph, Russia) and a standard ampulechromatographic procedure were used [16, 17]. The procedure was performed as follows: a $2-3 \mathrm{~g}$ test sample was placed into an ampule; the air medium was replaced by vacuum; the ampule was sealed and held at $+80{ }^{\circ} \mathrm{C}$ for $24 \mathrm{~h}$. The ampule was then opened and the released gaseous products were analyzed in order to identify the qualitative and quantitative composition of the gases. The sample was considered stable if the gas volume did not exceed $0.08-0.1 \mathrm{~cm}^{3} / \mathrm{g}$. The same procedure was employed to determine the chemical compatibility of the ingredients of the composite explosives.

The sensitivity of the nitrotriazole derivatives towards mechanical stimuli was measured by the standard techniques [18, 19] using a K-44-II impacttesting machine and a K-44-III friction-testing machine (Russia). The sensitivity measurement methods consisted in initiating a chemical reaction by impact or friction. For the impact stimulus, the Kozlov's K-44-II impacttesting machine was used. The impact tester consisted of a massive slab located on a solid concrete foundation and three guide supports between which there was a load weight fixed at a certain height. The load weight was intended to impact a test specimen. The test specimen was $0.05-0.1 \mathrm{~g}$ and was fixed in a special clutch. The standard technique involved the measurement of the socalled lower limit of sensitivity by dropping a $10-\mathrm{kg}$ weight from a height of $250 \mathrm{~mm}$. Ten to twenty five tests were done and the number of explosions were documented. Next, the relative incidence rate $(\%)$ of explosions was estimated $[18,20]$. 
The friction sensitivity was determined by the standard method for friction measurement under impact shear on a K-44-3 friction tester (the Kozlov's pendulum testing machine). The method was based on measuring the so-called lower limit of sensitivity being defined by the maximum application pressure under which the test specimen did not detonate. The test specimen was fixed between two steel plates moving by $1.5 \mathrm{~mm}$ relative to each other in 25 tests $[19,20]$. Test specimens were 0.02 $-0.05 \mathrm{~g}$. The pressure was defined from special tables, depending on the angle $\left(28-108^{\circ}\right)$ of the diversion of the instrument lever with the load weight [19].

The Excel and Mathcad universal mathematical programs were employed for the approximation of experimental data [21].

\section{Results and discussion}

The sensitivity of high-energy materials is one of the most essential characteristics because it determines the production and application safety levels of composite explosives. For instance, the impact sensitivity of 2,4,6trinitromethylbenzene (TNT) is 4-8\% [22] with a weighed portion of $0.05 \mathrm{~g}$, a drop height of $250 \mathrm{~mm}$, and a drop weight of $10 \mathrm{~kg}$; the friction sensitivity is 300 $\mathrm{MPa}$ [23]. 2,4-Dinitrazapentane (DNP) has similar characteristics: 5-10\% at the same drop height and weight [24]. The probability of explosion due to impact for 3,4-bis(4-nitrofurazanyl-3)furoxane (BNFF) is 80-96 $\%$ at a height of $250 \mathrm{~mm}$ and a load weight of $10 \mathrm{~kg}$, and the friction sensitivity is $44-60 \%$. [25]. Hence, TNT is the least sensitive and BNFF is the most sensitive among these compounds.

In comparison with TNT, the nitrotriazole derivatives (EOM, $2 \mathrm{Me} 3 \mathrm{H}, \mathrm{Me} 3 \mathrm{H}$ and $\mathrm{tBu} 3 \mathrm{H}$ ) are practically safe. The experimental data corroborate this statement: no explosion occurred in 25 tests (i.e. $0 \%$ ) and the lower limit of the friction sensitivity was therefore 10000 $\mathrm{kgf} / \mathrm{cm}^{2}$ (980.66 $\left.\mathrm{MPa}\right)$. The impact sensitivity was $\geq 500$ $\mathrm{mm}$ at a drop weight of $10 \mathrm{~kg}$. So, the addition of some BNFF to the nitrotriazole derivatives should not have a considerable influence on the sensitivity of the binary fusible binder.

Besides the sensitivity, it is necessary to determine other basic characteristics of the starting components. The melting temperature of the binder additive is of great importance because it has a bearing on the production process and storage of a finished explosive formulation. In some researchers' opinion [8], the melting temperature must be in the range from +80 to $+100{ }^{\circ} \mathrm{C}$. Our experience shows that the temperature of $+50-60{ }^{\circ} \mathrm{C}$ is enough.

Accoding to DSC tests (Table 1) samples were heated to $+125^{\circ} \mathrm{C}$ and the following parameters were determined: onset temperature of heat effect $\left(T_{b}\right)$, melting temperature $\left(\mathrm{T}_{\mathrm{m}}\right)$, endset temperature of heat effect $\left(\mathrm{T}_{\mathrm{e}}\right)$, melting heat $\left(\mathrm{Q}_{\mathrm{m}}\right)$. The sign '-'(minus) stands for heat absorption (endothermic effect). $\mathrm{T}$

he results in Table 1 demonstrate that the melting point of $2 \mathrm{Me} 3 \mathrm{H}$ is close to that of TNT, and the melting point of EOM is close to that of DNP. The compound
$\mathrm{tBu} 3 \mathrm{H}$ is more high-melting than the conventional fusible binders TNT and DNP. The compound $\mathrm{Me} 3 \mathrm{H}$ is a medium variant with $\mathrm{T}_{\mathrm{m}}=65.9{ }^{\circ} \mathrm{C}$. For BNFF, the melting point is $110.3{ }^{\circ} \mathrm{C}$, which is in agreement with the literature data $[6,8,26]$.

Table 1. Parameters of the starting compounds.

\begin{tabular}{|c|c|c|c|c|}
\hline \multirow{2}{*}{ Compound } & \multicolumn{4}{|c|}{ Parameters } \\
\cline { 2 - 5 } & $\mathbf{T}_{\mathbf{b}},{ }^{\circ} \mathbf{C}$ & $\mathbf{T}_{\mathbf{e}},{ }^{\circ} \mathbf{C}$ & $\mathbf{T}_{\mathbf{m}},{ }^{\circ} \mathbf{C}$ & $\mathbf{Q}_{\mathbf{m}}, \mathbf{J} / \mathbf{g}$ \\
\hline EOM & 55.1 & 59.3 & 56.4 & -156.1 \\
\hline tBu3H & 90.6 & 95.8 & 93.8 & -102.5 \\
\hline Me3H & 64.1 & 68.9 & 65.9 & -117.4 \\
\hline $2 \mathrm{Me} 3 \mathrm{H}$ & 79.3 & 84.5 & 81.2 & -104.7 \\
\hline TNT & 77.8 & 81.7 & 80.1 & -102.7 \\
\hline DNP & 53.7 & 58.1 & 55.2 & -100.1 \\
\hline BNFF & 108.6 & 111.7 & 110.3 & -96.6 \\
\hline
\end{tabular}

Since binary eutectic mixtures have a significantly lower melting point than each of the components, it is fair to expect that fusible binder additives based on BNFF will turn to the liquid state at a temperature below $90{ }^{\circ} \mathrm{C}$. Thus, a fusible additive can be obtained with an improved energetic performance and desirable technological properties. The optimum component ratio can be determined after the measurement of $T_{b}$ and $T_{m}$ required for building a phase diagram. Below is shown how it can be achieved.

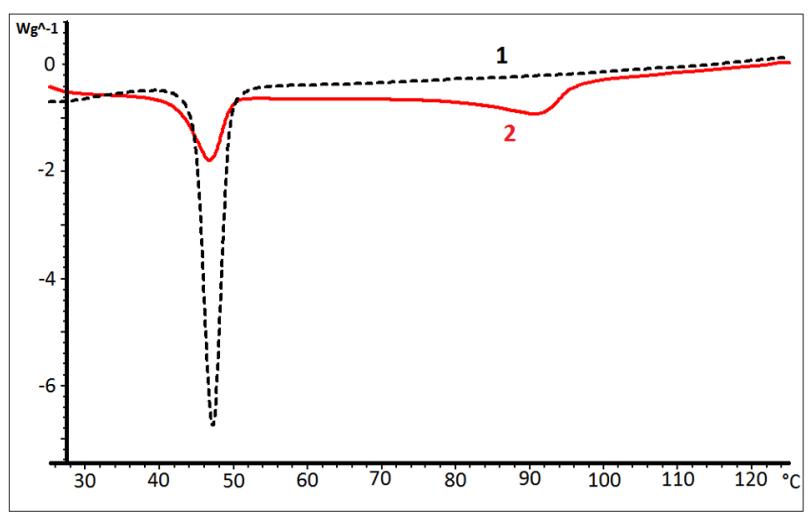

Fig. 1. DSC curves of binary eutectic melts: $1-60 / 40$ EOM/BNFF; 2 - 40/60 EOM/BNFF.

Fig. 1 illustrates DSC curves of fusible binder additives containing 60/40 \% EOM/BNFF (Fig. 1, black line) and 40/60\% EOM/BNFF (Fig.1, red line). It is obvious that one melting effect $\left(\mathrm{T}_{\mathrm{m} 1}\right)$ is present on the DSC curve of 60/40 EOM/BNFF; on the DSC curve of $40 / 60 \mathrm{EOM} / \mathrm{BNFF}$, two melting effects are present $\left(\mathrm{T}_{\mathrm{m} 1}\right.$ and $\mathrm{T}_{\mathrm{m} 2}$ ). The binder additives with component ratios of 
20/80, 50/50 and 80/20 refer to DSC curves resembling those of $40 / 60 \mathrm{EOM} / \mathrm{BNFF}$, i.e. to the curves having two melting effects. Hence, the melting of EOM/BNFF can take place in two different temperature ranges (Table 2).

Table 2. Parameters of fusible EOM/BNFF binder additives

\begin{tabular}{|c|c|c|c|c|c|}
\hline \multirow{2}{*}{ Compound } & \multicolumn{5}{|c|}{ BNFF content, \% } \\
\cline { 2 - 6 } & $\mathbf{2 0}$ & $\mathbf{4 0}$ & $\mathbf{5 0}$ & $\mathbf{6 0}$ & $\mathbf{8 0}$ \\
\hline $\mathrm{T}_{\mathrm{b} 1},{ }^{\circ} \mathrm{C}$ & 45.5 & 45.3 & 44.6 & 42.9 & 42.1 \\
\hline $\mathrm{T}_{\mathrm{m} 1},{ }^{\circ} \mathrm{C}$ & 46.5 & 46.8 & 46.7 & 47.4 & 46.8 \\
\hline $\mathrm{T}_{\mathrm{b} 2},{ }^{\circ} \mathrm{C}$ & 50.3 & - & 58.3 & 77.9 & 91.5 \\
\hline $\mathrm{T}_{\mathrm{m} 2},{ }^{\circ} \mathrm{C}$ & 52.6 & - & 67.2 & 85.8 & 99.9 \\
\hline $\mathrm{Q}_{\mathrm{m}}, \mathrm{J} / \mathrm{g}$ & -89.1 & -59.1 & -69.9 & -73.7 & -89.3 \\
\hline
\end{tabular}

The analysis of the results listed in Table 2 showed that the onset melting $\left(T_{b 1}\right)$ values were close; whichever the BNFF content was, the $\mathrm{T}_{\mathrm{b} 1}$ parameter differed by no more than $\pm 1.7{ }^{\circ} \mathrm{C}$. The melting points $\left(\mathrm{T}_{\mathrm{m} 1}\right.$, the first peak) differed by no more than $\pm 0.5^{\circ} \mathrm{C}$. The mean value of $\mathrm{T}_{\mathrm{m} 1}$ was $46.8^{\circ} \mathrm{C}$. This temperature is eutectic. The ongoing melting process and its onset temperature $\left(\mathrm{T}_{\mathrm{m} 1}\right.$ and $\mathrm{T}_{\mathrm{b} 2}$, the second peak), as well as the $\mathrm{Q}_{\mathrm{m}}$ heat effect values, were significantly distinct and depended on the BNFF content.

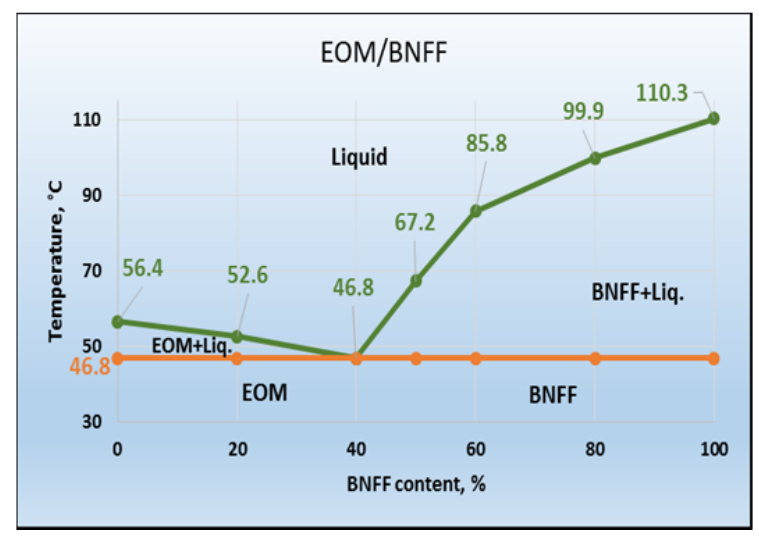

Fig. 2. Phase diagram of EOM/BNFF

From the results in Table 2, a phase diagram for the fusible EOM/BNFF binder additive can be built using the BNFF melting point and content. In Fig. 2, the straight orange line denotes the eutectic temperature, and the green line stands for the change in $\mathrm{T}_{\mathrm{m} 2}$. According to the diagram, the fully eutectic system corresponds to $60 / 40 \mathrm{EOM} / \mathrm{BNFF}$, while the other fusible additives of this type represent composites comprising some quantities of the eutectic system and starting materials. Thus, the contents of EOM and BNFF have an effect on the transition temperature of the fusible binder into the liquid state, which on the whole allows desired technological properties to be obtained.

Table 3. $\mathrm{T}_{\mathrm{b} 2}$ of fusible binder additives, ${ }^{\circ} \mathrm{C}$.

\begin{tabular}{|c|c|c|c|c|c|}
\hline \multirow{2}{*}{ Compound } & \multicolumn{5}{|c|}{ BNFF content, \% } \\
\cline { 2 - 6 } & $\mathbf{2 0}$ & $\mathbf{4 0}$ & $\mathbf{5 0}$ & $\mathbf{6 0}$ & $\mathbf{8 0}$ \\
\hline $\mathrm{tBu} 3 \mathrm{H}$ & 85.5 & 74.4 & 62.5 & 73.4 & 94.1 \\
\hline $\mathrm{Me} 3 \mathrm{H}$ & 59.1 & 51.5 & 47.0 & 69.8 & 93.1 \\
\hline $2 \mathrm{Me} 3 \mathrm{H}$ & 72.5 & 63.7 & 58.3 & 69.6 & 91.8 \\
\hline $\mathrm{TNT}$ & 71.8 & 57.0 & 70.1 & 81.2 & 96.7 \\
\hline $\mathrm{DNP}$ & 45.6 & 36.4 & 57.7 & 73.6 & 93.8 \\
\hline
\end{tabular}

Thus, the DSC technique was able to determine the temperatures of the binary eutectic composites and the approximate ratio of the starting components required to form a pure eutectic system. To refine the parameters of the pure eutectic mixture, more detailed experiments can be done with a greater diversity of the fusible EOM/BNFF additive. This can also be achieved by using the values of the heat effects to build a plot of $Q_{m}$ versus the BNFF content (Table 2). The third-degree polynomal approximation of the experimental data makes it possible to find the coordinates of the extremum whose abscissa corresponds to a more accurate content of the ingredients in the eutectic mixture. For the EOM/BNFF additive, this ratio is $58.5 / 41.5$.

By using the algorithm described above, all the binary fusible binders such as $\mathrm{tBu} 3 \mathrm{H} / \mathrm{BNFF}$, $\mathrm{Me} 3 \mathrm{H} / \mathrm{BNFF}, \quad 2 \mathrm{Me} 3 \mathrm{H} / \mathrm{BNFF}, \quad \mathrm{TNT} / \mathrm{BNFF}$ and $\mathrm{DNP} / \mathrm{BNFF}$ were studied. The results are summarized in Tables 3 and 4.

Phase diagrams of DNP/BNFF (Fig. 2) and $2 \mathrm{Me} 3 \mathrm{H} / \mathrm{BNFF}$ (Fig 3) were constructed from the data in Tables 3 and 4 . Table 5 lists characteristics of eutectic systems for all the fusible additives. The $T_{b}$ parameter for each type of binder additives was obtained by averaging the corresponding melting temperatures in five experiments; the component ratios were calculated mathematically. The results obtained for TNT/BNFF are on a par with those of other researchers [8].

The data in Table 5 show that in order to form pure eutectic systems, it is required that the nitrotriazole derivatives be mixed with a sufficiently larger amount of furazanyl furoxane $(41.5-52.8 \%)$; moreover, the melting temperatures of pure eutectic systems based on $\mathrm{Me} 3 \mathrm{H}$ and $\mathrm{EOM}$ are below $50{ }^{\circ} \mathrm{C}$, which is undesirable. The TNT/BNFF and DNP/BNFF eutectic mixtures contain a less amount of BNFF (37.6\% and $36.4 \%$ ), but they must have a higher sensitivity than TNT and DNP. Besides, the DNP/BNFF eutectic system has a too low melting point $\left(35^{\circ} \mathrm{C}\right)$, which is absolutely unacceptable. 
Table 4. $\mathrm{Q}_{\mathrm{m}}$ of fusible binder additives, $\mathrm{J} / \mathrm{g}$.

\begin{tabular}{|c|c|c|c|c|c|}
\hline \multirow{2}{*}{ Compound } & \multicolumn{5}{|c|}{ BNFF content, \% } \\
\cline { 2 - 6 } & $\mathbf{2 0}$ & $\mathbf{4 0}$ & $\mathbf{5 0}$ & $\mathbf{6 0}$ & $\mathbf{8 0}$ \\
\hline tBu3H & -98.3 & -53.2 & -50.1 & -50.4 & -85.8 \\
\hline $\mathrm{Me} 3 \mathrm{H}$ & -92.1 & -76.0 & -72.1 & -77.6 & -85.8 \\
\hline $2 \mathrm{Me} 3 \mathrm{H}$ & -78.3 & -63.9 & -61.2 & -61.8 & -75.4 \\
\hline $\mathrm{TNT}$ & -61.9 & -59.1 & -62.5 & -68.1 & -86.5 \\
\hline $\mathrm{DNP}$ & -69.1 & -68.1 & -71.5 & -73.5 & -94.6 \\
\hline
\end{tabular}

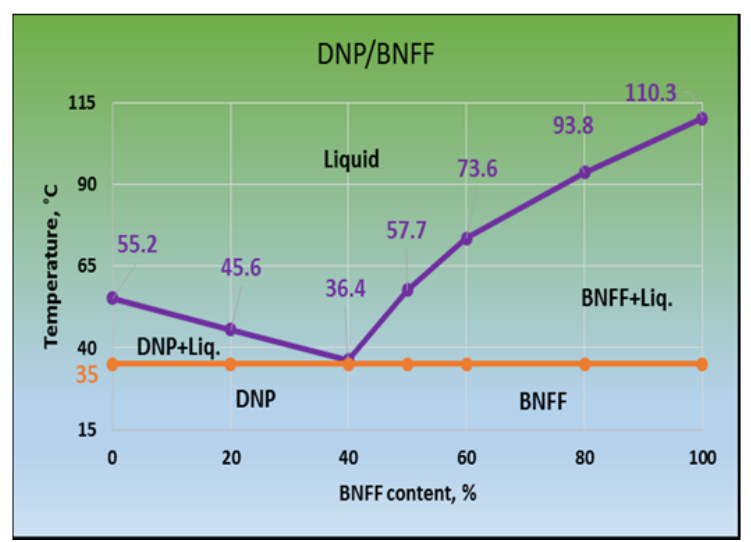

Fig. 3. Phase diagram of DNP/BNFF

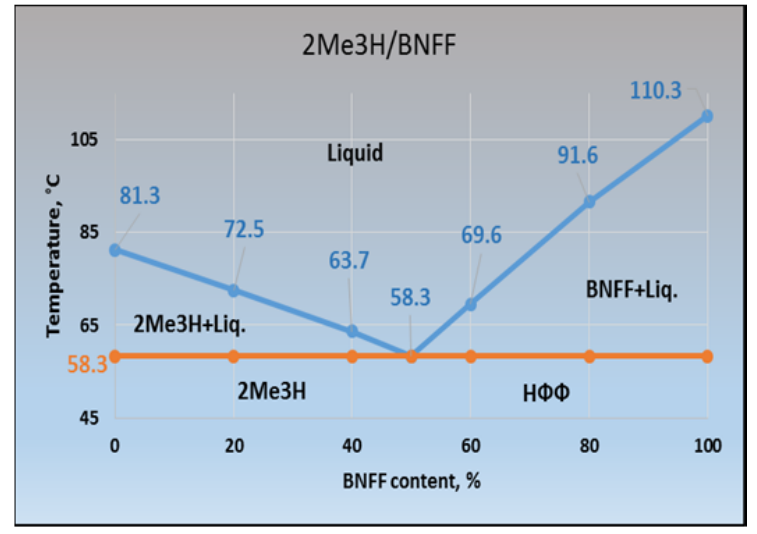

Fig. 4. Phase diagram of $2 \mathrm{Me} 3 \mathrm{H} / \mathrm{BNFF}$

In the storage of composite explosives, the stability of finished materials is of significant importance. Therefore, when designing composite explosives, it is necessary to examine the chemical compatibility of ingredients. It is known [8] that TNT is compatible with BNFF and HMX but is poorly compatible with CL-20 [27]. Initially, the compatibility can visually be checked by optical microscopy from the change in the surface morphology of HMX and CL-20 crystals.
Table 5. BNFF content and $T_{b}$ of eutectic systems.

\begin{tabular}{|c|c|c|}
\hline Compound & BNFF, $\%$ & $\mathbf{T}_{\mathbf{b}},{ }^{\circ} \mathbf{C}$ \\
\hline $\mathrm{tBu} 3 \mathrm{H}$ & 51.2 & 62.3 \\
\hline $\mathrm{Me} 3 \mathrm{H}$ & 52.8 & 46.7 \\
\hline $2 \mathrm{Me} 3 \mathrm{H}$ & 52.6 & 58.3 \\
\hline $\mathrm{EOM}$ & 41.5 & 46.8 \\
\hline $\mathrm{TNT}$ & 37.6 & 56.0 \\
\hline $\mathrm{DNP}$ & 36.4 & 35.0 \\
\hline
\end{tabular}

Fig. 5 shows a photograph of CL-20 crystals, and Fig. 6 displays the crystals after they resided in the molten $2 \mathrm{Me} 3 \mathrm{H}$ at $80{ }^{\circ} \mathrm{C}$ for $30 \mathrm{~min}$. The images were taken at $\mathrm{x} 400$ zoom.

It is clearly seen in Fig. 5 that the crystals have a certain shape and a smooth surface. Fig. 6 illustrates how $2 \mathrm{Me} 3 \mathrm{H}$ reacts with CL-20: the crystals lost their original shape and partially their volume. Hence, these ingredients are poorly compatible. A similar picture was observed after the HMX crystals were present in the $2 \mathrm{Me} 3 \mathrm{H}$ melt. The HMX surface was highly damaged, although the crystals themselves retained the initial shape. The other nitrotriazole derivatives did not have such an effect on HMX and CL-20.

Sometimes, the chemical compatibility or its absence can be determined by the DSC technique. For instance, BNFF was shown to be incompatible with CL-20 [28]. However, this technique is not always effective. The reliable method in studying high-energy materials and their components is chromatography, which can provide a qualitative and quantitative outcome. The chromatographic study of the chemical compatibility between $\mathrm{tBu} 3 \mathrm{H}, \mathrm{EOM}, \mathrm{Me} 3 \mathrm{H}$ and $\mathrm{HMX}$ demonstrated that the gas release was $0.05 \mathrm{~cm}^{3} / \mathrm{g}$. This quantity suggests a good compatibility between the ingredients.

Table 6 summarizes the measurement data for composite explosives with conventional and new fusible binder additives. For the safety purpose, the binary fusible additives were prepared with a low amount of BNFF $(20 \%)$. The parameters $T_{d}$ (temperature extremum of decomposition) and $\mathrm{Q}_{\mathrm{d}}$ (heat effect value on the DSC curve; the sign '+' (plus) stands for heat release) listed in Table 6 allow us to judge about the heat-generating capacity of the decomposition reactions taking place when the composites are heated up to +350 ${ }^{\circ} \mathrm{C}$. 


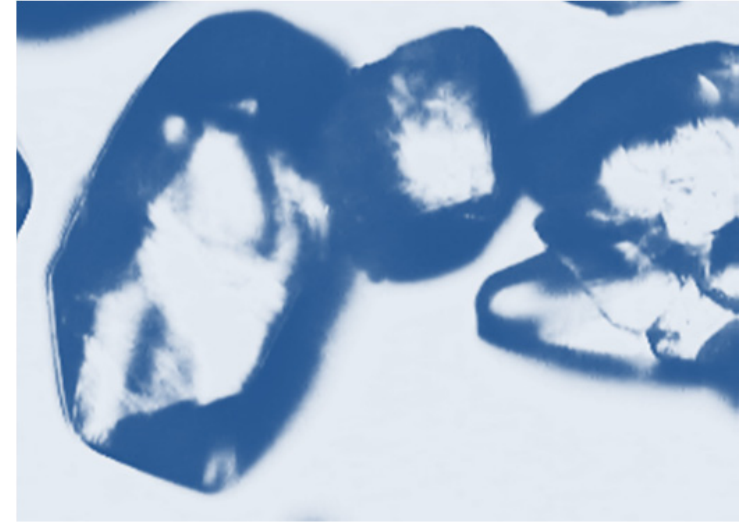

Fig. 5. Original CL-20 crystals (x400)

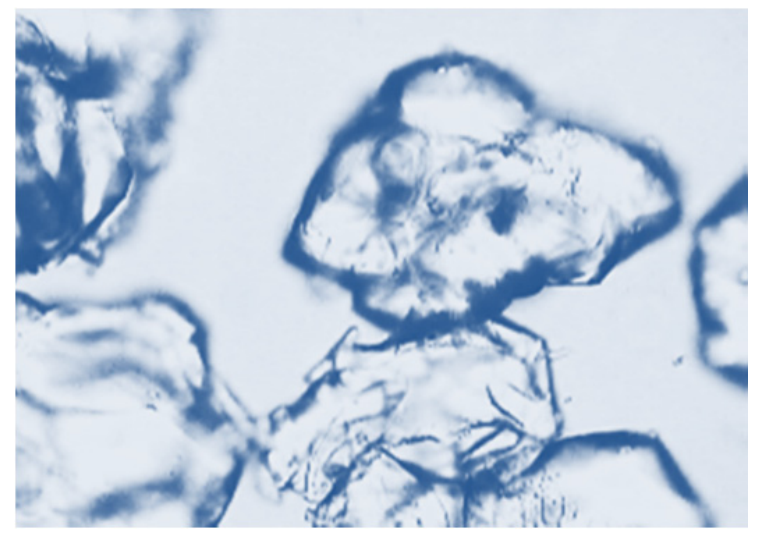

Fig. 6. CL-20 crystals after residence in molten $2 \mathrm{Me} 3 \mathrm{H}(\mathrm{x} 400)$

Table 6. Parameters of composite explosives.

\begin{tabular}{|c|c|c|c|c|}
\hline \multirow{2}{*}{ Compound } & \multicolumn{2}{|c|}{ HMX } & \multicolumn{2}{|c|}{ CL-20 } \\
\hline & $\mathrm{T}_{\mathrm{d}},{ }^{\circ} \mathrm{C}$ & $\mathrm{Q}_{\mathrm{d}}, \mathrm{J} / \mathrm{g}$ & $\mathrm{T}_{\mathrm{d}},{ }^{\circ} \mathrm{C}$ & $\mathrm{Q}_{\mathrm{d}}, \mathrm{J} / \mathrm{g}$ \\
\hline $\mathrm{tBu} 3 \mathrm{H}$ & 284.9 & +1014.4 & 221.4 & +1469.2 \\
\hline $\mathrm{Me} 3 \mathrm{H}$ & 285.3 & +1006.1 & 225.1 & +1859.2 \\
\hline $2 \mathrm{Me} 3 \mathrm{H}$ & 287.6 & +1379.2 & 253.7 & +2226.3 \\
\hline EOM & 278.9 & +1127.2 & 221.7 & +1529.9 \\
\hline $\begin{array}{c}\text { 80/20 } \\
\text { EOM/BNFF }\end{array}$ & 277.3 & +1193.5 & 225.4 & +1648.7 \\
\hline $\begin{array}{c}80 / 20 \\
\mathrm{Me} 3 \mathrm{H} / \mathrm{BNFF}\end{array}$ & 276.7 & +712.5 & 224.7 & +2086.7 \\
\hline $\begin{array}{c}\text { 80/20 } \\
\text { TNT/BNFF }\end{array}$ & 297.7 & +1048.1 & 224.7 & +1079.0 \\
\hline $\begin{array}{c}80 / 20 \\
\text { DNP/BNFF }\end{array}$ & 276.7 & +1253.2 & 225.9 & +1749.3 \\
\hline
\end{tabular}

The amount of heat release during pyrolysis of a composite explosive is the most essential parameter that can preliminarily predict the performance capability of one composite explosive or another. The greater the heat release, the better. It follows from Table 6 that the highest heat release can be obtained if $2 \mathrm{Me} 3 \mathrm{H}$ is used $\left(\mathrm{Q}_{\mathrm{d}}=+1379.2 \mathrm{~J} / \mathrm{g}\right.$ with HMX; $\mathrm{Q}_{\mathrm{d}}=+2226.3 \mathrm{~J} / \mathrm{g}$ with CL-20). However, as is shown above, these components exhibited a poor chemical compatibility and their mixtures were unstable. The $\mathrm{tBu} 3 \mathrm{H}$ and $\mathrm{tBu} 3 \mathrm{H} / \mathrm{BNFF}$ additives were very high-melting for processing (Table 2 ). The fusible $80 / 20 \mathrm{DNP} / \mathrm{BNFF}$ additive demonstrated a quite good result $\left(\mathrm{Q}_{\mathrm{d}}=+1749.3 \mathrm{~J} / \mathrm{g}\right)$ with $\mathrm{CL}-20$ but its melting temperature was low $\left(\mathrm{T}_{\mathrm{m} 2}=45.6{ }^{\circ} \mathrm{C}\right)$, and it had a higher sensitivity than DNP. Thus, the following options are available: EOM, Me $3 \mathrm{H}$ and their binary fusible mixtures with BNFF (20\%). The fusible EOM and 80/20 EOM/BNFF additives are suitable for composites with HMX, while $\mathrm{Me} 3 \mathrm{H}$ and 80/20 $\mathrm{Me} 3 \mathrm{H} / \mathrm{BNFF}$ are appropriate for CL-20.

\section{Conclusion}

New insensitive fusible binder additives have been suggested herein for composite explosives. The experimental results demonstrated that for CL-20-based formulations, the optimum additives were 1-methyl-3nitro-1,2,4-triazole and its eutectic melt with BNFF (20 $\%$ ), while for HMX-based formulations, it was better to use ethoxymethyl-3-nitro-1,2,4-triazole and its melt with furazanyl furoxane $(20 \%)$. In future, the component database of insensitive fusible additives based on nitrotriazole derivatives needs to be diversified by means of conventional materials (TNT, DNP, etc.).

This study was supported by Project No. 0385-2018-0009 and performed using instruments from the Biysk Regional Center for Shared Use of Scientific Equipment (IPCET SB RAS, Biysk).

\section{References}

1. M.S. Pevzner, Rus.J. Gen. Chem. 41, 2, 73 (1997)

2. D.A. Pytakov, B.M. Chernyshev High Energy Materials on Base of Heterocycle (NOK-publishers, Novocherkassk, 2013)

3. A.B. Burzhava, V.P. Sinditskii, A.B. Sheremetov. Advances in Chemistry and Chemical Technology, 25, 12, 72 (2011)

4. X. Li, B.-L. Wang, Q.-H. Lin, L.-P. Chen, J. Energet. Mater. 34, 409 (2016)

5. W. Zheng, J.-N. Wang, Chin. J. Energet. Mater. 14, 6, 463 (2006)

6. V.P. Sinditskii, A.V. Burzhava, A.B. Sheremetev, N.S. Aleksandrova, Propellants, Explos. Pyrotech., 37, 573 (2012)

7. F.-Q. Zhao, P. Chen, R.-Z. Hu, Y. Luo, Z.-Z. Zhang, Y.-S. Zhou, X.-W. Yang, Y. Gao, S.-L. Gao, Q.-Z. Shi, J. Hazard. Mater. A113, 67 (2004) 
8. Q.-H. Wang, Chin. J. Energet. Mater. 12, 1, 46 (2004)

9. M.V. Komarova, A.G. Vakutin, N.V. Kozyrev, S.G. Il'yasov, South-Siberian Scientific Bulletin 4, 135 (2017)

10. G.T. Sukhanov, A.Yu. Lukin, Chem. Heterocycl. Compd. 7, 1020 (2005)

11. A.G. Sukhanova, G.V. Sakovich, G.T. Sukhanov, Chem. Heterocycl. Compd. 11, 1680 (2008)

12. G.T. Sukhaniv, A.G. Sukhanova, K.K. Bosov, Yu.V. Filippova, V.A. Istoshina, I.A. Krupnova, South-Siberian Scientific Bulletin, 4, 182 (2017)

13. S.F. Melnikova, I. Tselinskiy, Bullet of St PbSIT(TU) 21, 25 (2013)

14. W.W. Wendlandt Thermal Methods of Analysis (Mir-publishers, Moscow, 1978)

15. M. Wagner Thermal Analysis in Practice (MettlerToledo AG, Schwerzenbach, 2009)

16. B.L. Korsunskiy, G.B. Manelis, G.M. Nazin, P.N. Stolyarov, Russian J. General Chem. E 41, 4, 37 (2007)

17. K.I. Sakodynskiy Analytical Chromatography (Khimiya Publisher, Moscow, 1993)

18. GOST RF 4545-88 Explosives, high. Sensitivity characteristics determination for impact (Standartpublishers, Moscow, 1988)
19. GOST R 50835-95 Explosives, high. Methods for determination of sensitivity characteristics to friction at impact displacement (Standartpublishers, Moscow, 1996)

20. L.V. Fomicheva Explosives. Basic Properties. Production and Processing Technology. P. 2 (RFNC-VNIIEF, Sarov, 2007)

21. I.I. Kaganov Computer calculations in ambience EXCEL and MathCAD (South Ural-publishers, Orenburg, 2003)

22. L.I. Khmel'nitskiy A Reference Book of Explosives. P.2 (Moscow, 1962)

23. L.V. Dubnov, N.S. Bakharevich, A.I. Romanov Industrial Explosives (Nedrapublishers, Moscow, 1988)

24. V.A. Tartakovskiy, A.S. Ermakov, N.V. Sigay, O.N. Varfolomeeva, G.F. Tereschenko and etl., U.S. Patent No. 2,061,680 (10 June 1996)

25. Z.Y. Wang, B. Li, J.Z. Cheng, H.L. Chen, Z.Z. Zhizhong, Acta Chimica Sinica 69, 14, 1673 (2011)

26. A.I. Stepanov, D.V. Dashko, A.A. Astrat'ev, Cent. Eur. J. Energ. Mater. E 9, 4, 329 (2012)

27. M.V. Kazutin, N.V. Kozyrev, E.A. Petrov, M.V. Komarova, Polzuniv Proceedings [Polzunovsky vestnik - in Russian]1, 4, 40-44 (2016)

28. W. Zheng, J. Wang, X. Ren, L. Zhang, Y. Zhou, Propellants, Explos. Pyrotech. 32, 520 (2007) 